\title{
Testing the in vitro performance of hydroxyapatite coated magnesium (AZ91D) and titanium concerning cell adhesion and osteogenic differentiation
}

\begin{abstract}
In the current study the in vitro outcome of a degradable magnesium alloy (AZ91D) and standard titanium modified by nanostructured-hydroxyapatite (n-HA) coatings concerning cell adhesion and osteogenic differentiation was investigated by direct cell culture. The n-HA modification was prepared via radiofrequency magnetron sputtering deposition and proven by field emission scanning electron microscopy and X-ray powder diffraction patterns revealing a homogenous surface coating. Human mesenchymal stem cell (hMSCs) adhesion was examined after one and 14 days displaying an enhanced initial cell adhesion on the $n-H A$ modified samples. The osteogenic lineage commitment of the cells was determined by alkaline phosphatase (ALP) quantification. On day one n-HA coated AZ91D exhibited a comparable ALP expression to standard tissue culture polystyrene samples. However, after 14 days solely little DNA and ALP amounts were measurable on n-HA coated AZ91D due to the lack of adherent cells.
\end{abstract}

\footnotetext{
*Corresponding author: Petra Juliane Kluger, Fraunhofer IGB Stuttgart, Department of Cell and Tissue Engineering, Nobelstrasse 12, 70569 Stuttgart, Germany, Phone: +49-711-970-4072, Fax: +49-711-970-4158, E-mail: petra.kluger@igb.fraunhofer.de; Fraunhofer Institute for Interfacial Engineering and Biotechnology (IGB), 70569 Stuttgart, Germany; and Process Analysis and Technology (PA\&T), Reutlingen-University, 72762 Reutlingen, Germany

Claudia Kleinhans: Department of Orthopedics, Medical University Graz, 8036 Graz, Austria; and Institute for Interfacial Process Engineering and Plasma Technology IGVP, University of Stuttgart, 70569 Stuttgart, Germany

Gabriele Vacun: Fraunhofer Institute for Interfacial Engineering and Biotechnology (IGB), 70569 Stuttgart, Germany

Roman Surmenev: Fraunhofer Institute for Interfacial Engineering and Biotechnology (IGB), 70569 Stuttgart, Germany; and Department of Theoretical and Experimental Physics, National Research Tomsk Polytechnic University, 634050 Tomsk, Russia Maria Surmeneva: Department of Theoretical and Experimental Physics, National Research Tomsk Polytechnic University, 634050 Tomsk, Russia
}

Titanium displayed excellent cell adhesion properties and ALP was detectable after 14 days. An increased $\mathrm{pH}$ of the culture was measured for AZ91D as well as for n-HA coated AZ91D. We conclude that n-HA modification improves initial cell attachment on AZ91D within the first $24 \mathrm{~h}$. However, the effect does not persist for 14 days in in vitro conditions.

Keywords: cell adhesion; direct cell test; human mesenchymal stem cells; in vitro testing; magnesium alloys; nanostructured-hydroxyapatite coating; osteoinductivity.

DOI 10.1515/bnm-2015-0002

Received January 15, 2015; accepted April 28, 2015; previously published online May 23, 2015

\section{Introduction}

Magnesium (Mg) represents a promising material for the application in the field of orthopedic implants due to its biocompatibility, degradation properties and load bearing capacities $[1,2]$. The first magnesium-based screw was recently introduced to the clinical market; nevertheless, it is important to investigate the suitability of magnesium alloys in more detail [3, 4]. One important step is the in vitro testing prior to animal examination to pre-select promising material coatings or bulk compositions. However, the in vitro testing of degradable materials comprises several difficulties. Especially the direct cell culture on degradable biomaterials is challenging to realize. Degradation products may interfere with analysis methods [5] and influence cell adhesion after a prolonged culture period [6]. To test the biological outcome in vitro, mostly extraction tests were performed concerning biocompatibility [7], or one step further on cellular reactions such as alterations in gene expression [8] and the induction of osteogenic differentiation [9]. Direct cell material 
interactions are poorly performed as difficulties occur in prolonged culture periods [6].

Magnesium alloys of different compositions have been fabricated addressing for example antimicrobial properties by adding silver [10], or composites with hydroxyapatite (HA) to influence degradation rate and bioactivity [11]. Several coating techniques were applied to reduce the degradation velocity as one drawback of magnesium is the rapid corrosion rate associated with hydrogen gas formation [12-14]. Surface coatings initially shield the bulk material from the environment and thus degradation may be retarded [15]. Furthermore, cell adhesion can be influenced by surface modifications such as surface topography [16-18], chemical composition [19], or introduced protein layers or peptides [20,21]. HA coatings were applied in several studies leading to a slower corrosion rate [12, 13, 22, 23]. Furthermore, it could be shown that the bioactivity of the material was improved in terms of biocompatibility and osteoconductivity. Therefore, surface modifications present a useful tool to control cell behavior and to influence the degradation properties of $\mathrm{Mg}$ alloys.

In our study, we investigated the influence of a thin nanostructured-HA (n-HA) coating $650 \pm 50 \mathrm{~nm}$ thick, prepared via radio-frequency $(\mathrm{RF})$ magnetron sputtering deposition, on cell adhesion and osteogenic differentiation by a direct cell culture on the substrate up to 14 days. By plasma modification it is possible to introduce thin n-HA coatings that may be beneficial to thicker plasmasprayed coatings [24]. Sputtering offers the potential to produce dense and uniform coatings on metallic, ceramic or polymeric substrates [25]. Moreover, it allows the preparation of the coatings $<1 \mu \mathrm{m}$ thick with controlled microstructure which reduces the risk of third-body wear and subsequent osteolysis [24]. The adhesion of CaP-based coatings prepared via RF magnetron sputtering on metallic substrates is excellent; moreover, a beneficial biological response was observed both in vitro and in vivo in comparison with uncoated metals [26-30]. So far such thin coatings have not been applied on Mg alloys via $\mathrm{RF}$ magnetron sputtering and tested addressing osteoinductivity [15]. Thus, we tested the n-HA functionalization on magnesium alloy AZ91D and furthermore on standard non-degradable titanium as reference material. As human mesenchymal stem cells (hMSCs) differentiate in response to adequate stimuli to osteoblasts, we used these cells in our experiments. Prevalently, Mg and coating strategies were tested concerning their degradation rate in vitro. Few studies addressed the biological outcome by extraction testing or exposing cells to the material for a short culture period only [31-34]. We wanted to examine the in vitro performance of the n-HA coating in a biological milieu as well as to reconsider if a direct in vitro test set up is suitable for evaluating highly degradable materials in extended culture times.

\section{Results}

Field emission scanning electron microscope (FE-SEM) analysis was performed to analyze the surface morphology of n-HA films deposited via RF magnetron sputtering on AZ91D magnesium alloy, consisting in wt.\% of $\mathrm{Al}$ (8.77), Zn (0.74), Mn (0.18), Ni (0.001), Cu (0.001), Ca $(<0.01)$, Si $(<0.01), \mathrm{K}(<0.01)$, Fe $(<0.001), \mathrm{Mg}$ (balance), and titanium substrates (Figure 1A,B). It is seen from the FE-SEM image that a coating is homogeneously deposited onto the surface of the substrate. The HA coating fabrication process did not affect the surface morphology of the substrate and it was grown by uniformly replicating the surface topography of the substrate. The X-ray powder diffraction (XRD) patterns of the deposited coatings and uncoated substrates are shown in Figure $1 \mathrm{C}$ and D. In the case of the coated substrates, besides the peaks attributed to the substrate, only slightly broadened HA peaks, indicating a nanocrystalline structure of the coating, were found. The obtained XRD patterns of the coating showed broad overlapping peaks around $32^{\circ}$ which are also typical for a nanocrystalline material. No diffraction peaks from other phases such as calcium oxide (CaO), tricalcium phosphate (TCP) or tetracalcium phosphate (TTCP) were detected.

Osteogenic lineage commitment of hMSCs was evaluated by quantitative measurements of alkaline phosphatase (ALP) production that was normalized to total amount of DNA (Figure 2A,B). After 1 day of cell culture no ALP was measured on non-modified AZ91D samples (Figure 2A) associated with no detectable cells on the material (Figure 2C). The n-HA coated AZ91D and Tissue culture polystyrene (TCPS) revealed a similar ALP expression independent of the culture medium (Figure 2A). A dense cell layer was observed on AZ91D and n-HA comparable to TCPS in proliferative medium (control) and osteogenic medium (Figure 2C). After 14 days of cell culture no ALP was measurable on pure AZ91D, solely little amount of $58.88 \pm 58.89 \mathrm{ng}$ ALP/ $\mu \mathrm{g}$ DNA was detected for cells cultured on AZ91D n-HA in osteogenic medium. A strong ALP expression was proven when cells were cultured on TCPS in osteogenic medium with an expression of $359.39 \pm 77.23 \mathrm{ng} \mathrm{ALP} / \mu \mathrm{g}$ DNA that was significantly higher compared to cells kept in proliferative medium revealing 
51.71 $\pm 7.09 \mathrm{ng}$ ALP/ $\mu \mathrm{g}$ DNA. Immunofluorescence staining of actin and vinculin presented a dense cell layer on TCPS after 1 (Figure 2C) and 14 days (Figure 2D) of cells culture. No cells were detected on AZ91D, occasionally hMSCs could be found on n-HA coated AZ91D samples after 14 days (Figure 2D).

Same experiments were conducted on titanium and n-HA coated titanium. A dense cell layer was seen on all applied probes (Figure 3C) correlated with an ALP expression around 150-260 ng ALP/ $\mu$ g DNA. No significant differences were seen between HA coated and non-coated samples after 1 day of culture time (Figure 3A). After 14 days a manifest difference was detectable between hMSCs cultured in proliferation medium and osteogenic medium (Figure 3B). The highest ALP amount of $268.85 \pm 136 \mathrm{ng}$ $\mathrm{ALP} / \mu \mathrm{g}$ DNA aroused in cells on TCPS in osteogenic medium (Figure 3B). Comparable numbers of cells were detected on all substrates furthermore visually proven by actin and vinculin fluorescence staining (Figure 3D).

As it is well known that $\mathrm{Mg}$ degradation influences the local $\mathrm{pH}$ value, we estimated the $\mathrm{pH}$ shift in the culture medium over 13 days (Figure 4). A relatively constant $\mathrm{pH}$ value around 7.9 was detected for AZ91D and AZ91D n-HA until day 9, rising to 8.0 on day 13. AZ91D culture without coating developed a drop of the medium $\mathrm{pH}$ from 7.9/8.0 to around 7.8 on day 9. Depending on culture medium and coating, titanium samples displayed $\mathrm{pH}$ values in a range of 7.6-7.8 (Figure 4).

\section{Discussion}

Magnesium represents a most suitable material for the application in the orthopedic field. Advantages like degradation ability, biocompatibility, good bone integration, and mechanical properties make magnesium an optimal candidate as implant material. However, one drawback of the material is the fast corrosion rate. When magnesium alloys get in contact with a biological milieu corrosion products are released and gas formation occurs [35]. To prevent a too fast degradation and in addition to influence cell behavior allowing cell adhesion and integration into the host tissue, surface coatings could help to overcome these problems.

Calcium phosphate (CaP) coatings are promising approaches to decelerate $\mathrm{Mg}$ degradation and were applied in several studies. Due to the high reactivity of $\mathrm{Mg}$ and its relatively low melting point $\left(650^{\circ} \mathrm{C}\right)$, not all deposition methods of $\mathrm{CaP}$ coatings can be used for application
A

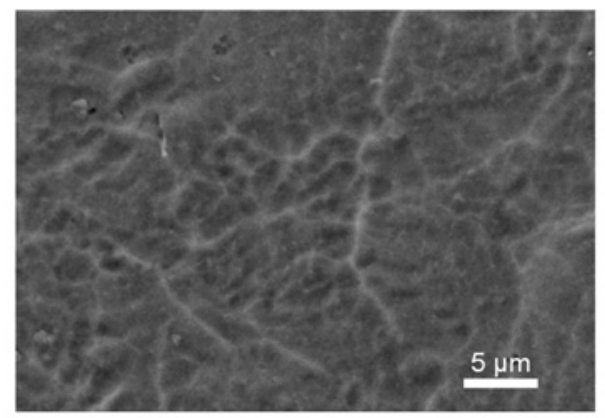

C

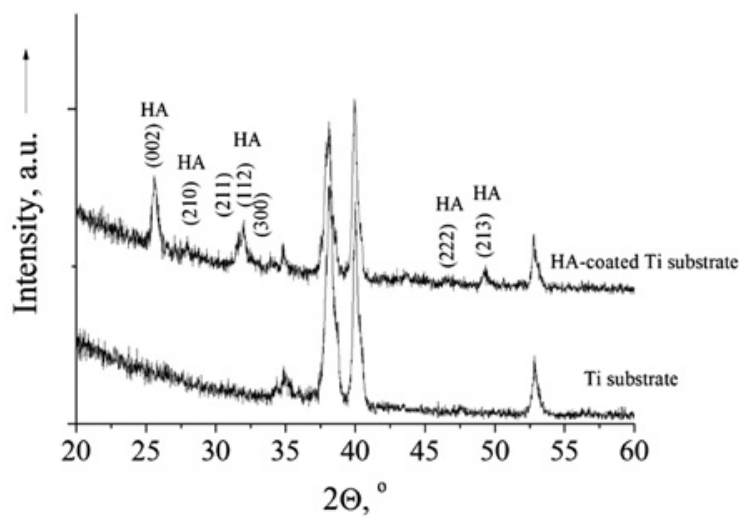

B

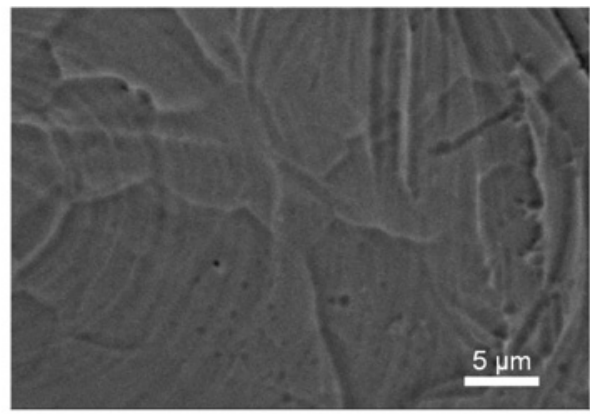

D

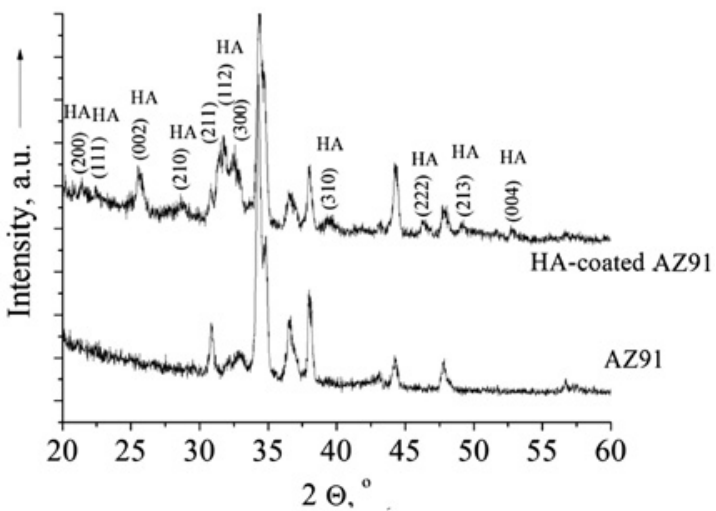

Figure 1: FE-SEM images (A, B) and X-ray powder diffraction patterns (C, D) of the surface of $700 \mathrm{~nm}$ thick HA film deposited via RF magnetron sputtering on Ti (A, C) and magnesium alloy AZ91D (B, D). 

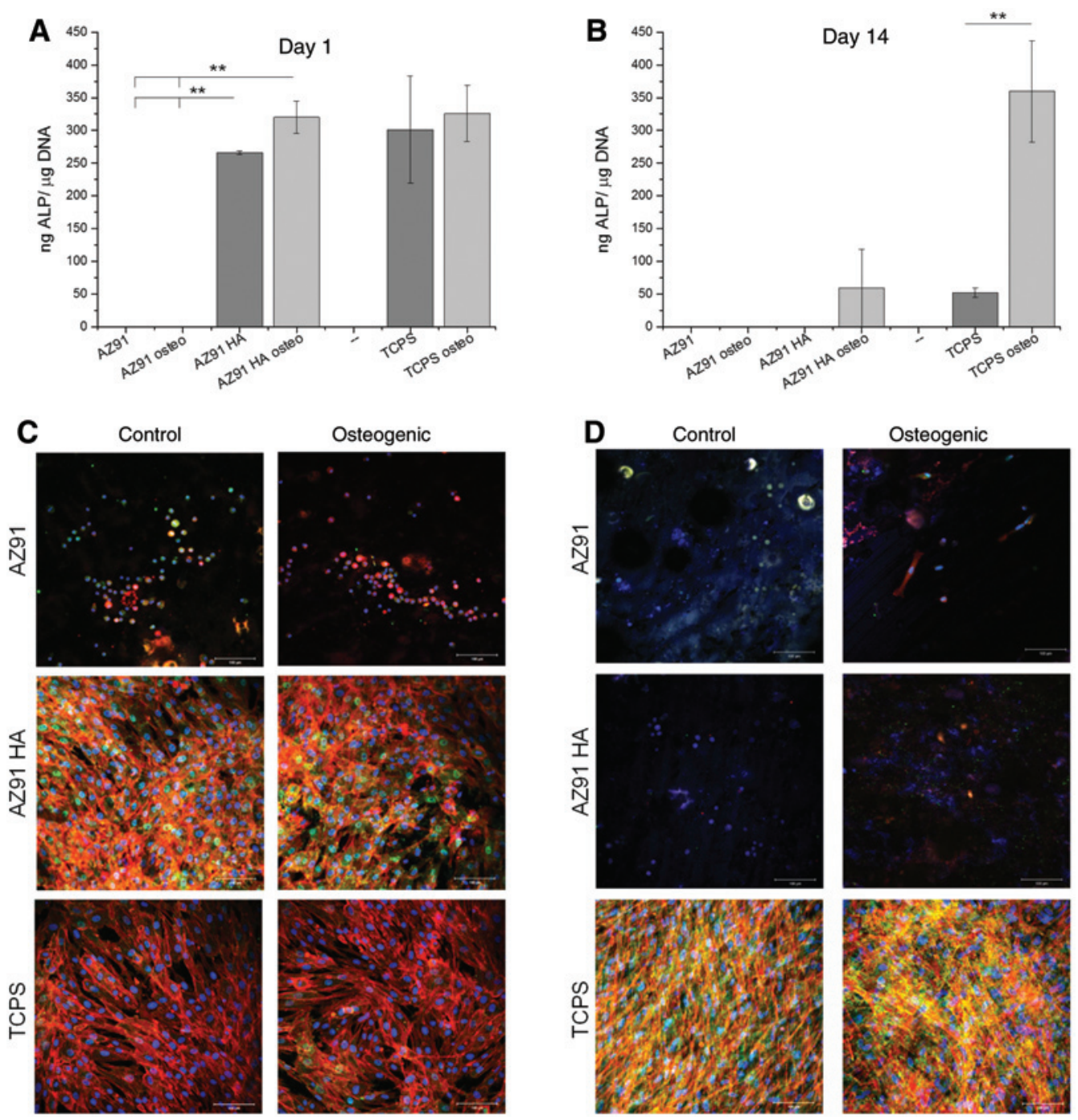

Figure 2: Osteogenic lineage commitment of hMSCS on AZ91D and AZ91D coated with HA was analyzed by ALP quantification on day 1 (A) and day 14 (B) normalized to total DNA. Cell adhesion was evaluated on day 1 (C) and day 14 (D) by fluorescence staining for actin (red) and vinculin (green) that are components of focal adhesions. Tissue culture polystyrene (TCPS) was used as control. Cells were either kept in proliferation medium (control) or in osteogenic medium (osteogenic). Data are shown as mean \pm SD whereas * denotes significant differences with ${ }^{*} \mathrm{p} \leq 0.05$ and ${ }^{* *} \mathrm{p} \leq 0.01 . \mathrm{n}=3$.

in case of magnesium substrates. Although the wet-chemical methods are suitable for deposition of CaP coating on the magnesium alloys, all these methods suffer from weak adhesive strength [24]. HA coatings fabricated via $\mathrm{RF}$ magnetron sputtering on titanium and its alloys have been described as dense, uniform, non-porous films [29, 30] and improved wear resistance compared to uncoated substrates [29, 30]. Moreover, for NiTi substrates, the average nickel release rate from the samples with a dense crystalline $700 \mathrm{~nm}$ thick HA coating deposited via RF magnetron sputtering was reduced by $7-10$ times relative to the uncoated substrates [36].

In our study, we applied a thin n-HA layer via RF magnetron sputtering on AZ91D to evaluate the influence on cell adhesion and osteogenic differentiation. As reference material Ti and TCPS were used. A thin nanostructured $650 \pm 50 \mathrm{~nm}$ thick RF magnetron sputter deposited coating was obtained on the surface of AZ91D magnesium alloy and titanium substrates. Each coating covered the entire surface of each sample and was homogeneously distributed over the entire surface. The coating structure corresponded to a nanostructured HA.

Another strategy was pursued by Johnson et al. that used electrospinning of nanostructured HA in combination with poly(lactic-co-glycolic acid) as surface treatment of AZ91 [37]. They postulated a slower degradation rate and a higher bioactivity resulting of the modification when examining in simulated body fluid. Rojaee et al. prepared 

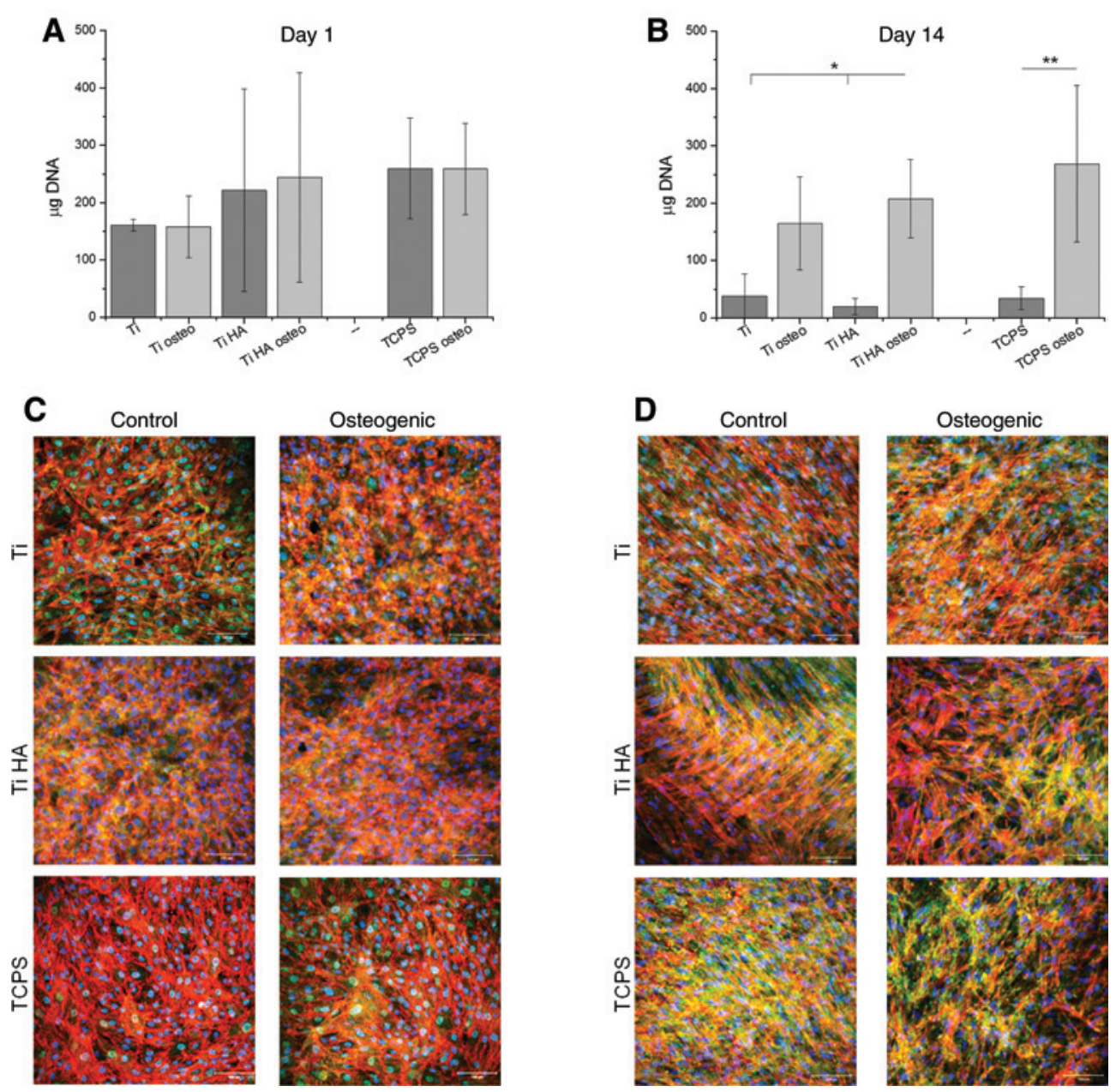

Figure 3: Analysis of cell adhesion and osteogenic differentiation by ALP quantification on day $1(\mathrm{~A})$ and day 14 (B) on titanium and $n$-HA modified titanium. As control samples served tissue culture polystyrene (TCPS). Cell adhesion was detected on day 1 (C) and day 14 (D) by fluorescence staining for actin (red) and vinculin (green) as parts of focal adhesion complexes. Cells were either cultured in proliferation medium (control) or in osteogenic medium (osteogenic). Data are shown as mean \pm SD whereas * denotes significant differences with ${ }^{*} \mathrm{p} \leq 0.05$ and ${ }^{* *} \mathrm{p} \leq 0.01 . \mathrm{n}=3$.
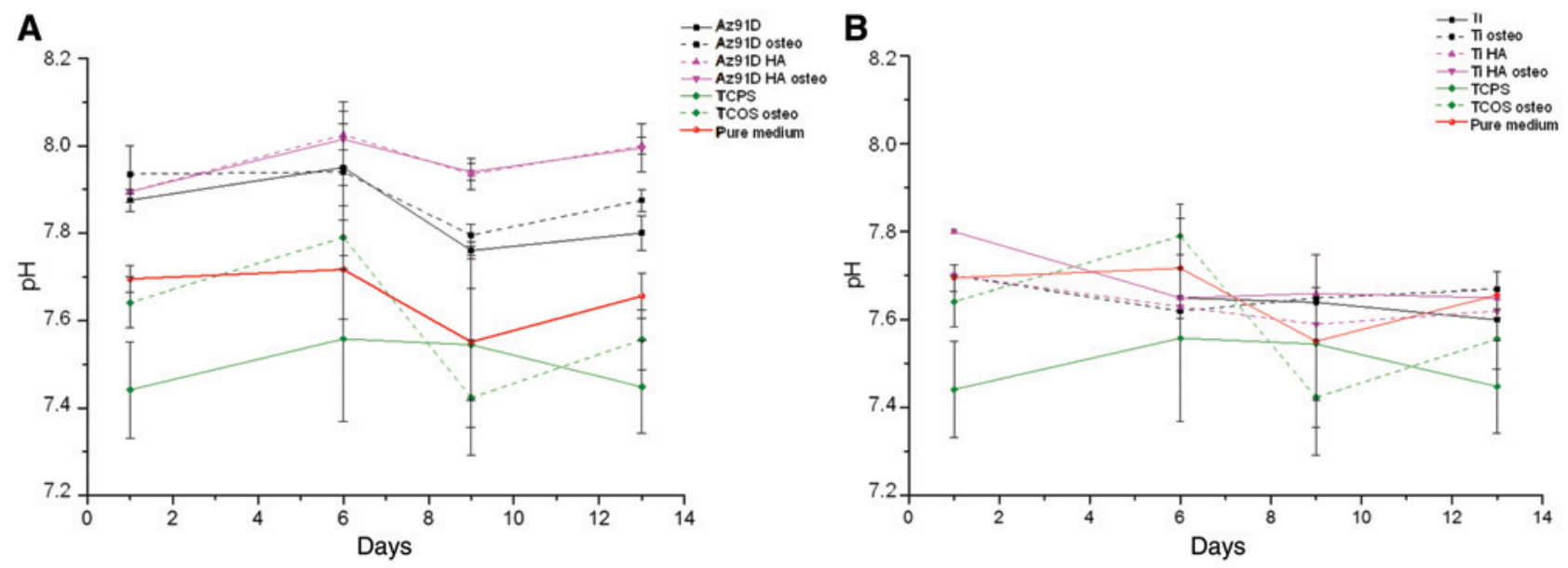

Figure 4: $\mathrm{pH}$ measurement of the culture medium within the culture period of 13 days for AZ91D (A) and Ti (B). 
a n-HA surface treatment of AZ91 magnesium alloy via electrophoretic deposition method. Tested in simulated body fluid, they showed that n-HA coated AZ91 Mg alloy samples with a rough topography led to lower $\mathrm{Mg}$ degradation rate accompanied by high bioactivity $[38,39]$.

Indirect extraction tests were applied to examine the cytotoxicity of the materials and coating by Gopi et al. Thereby, medium exposed to the samples was added on cells and subsequently cell viability was determined. They evaluated strontium-substituted HA/zinc oxide duplex layer on AZ91 by using the cell line human osteosarcoma MG63 [40]. Even if an extended culture period can be achieved and further parameter such as osteogenic induction can be evaluated [9], drawback of this method is the missing evaluation of direct cell-material interactions. A direct cell-material contact was performed in the study by Iskandar et al. [41]. They used polished pure (99.9\%) Mg that was modified by nanostructured HA via a transonic particle acceleration deposition process. Rat bone marrow stromal cells were cultured for $24 \mathrm{~h}$ on the modified and non-modified Mg showing adherent cells on both samples. They declared an enhanced effect of surface nanostructure and composition on cell activity. They also proposed further cell studies and animal studies to verify their results. In their study, they observed an increase of the $\mathrm{pH}$ in the culture medium exceeding 8.0. Johnson and his colleagues analyzed a Magnesium/Yttrium alloy seeing also a shift in the $\mathrm{pH}$ in the culture medium to alkaline conditions [32]. Goat MSCs were directly culture on the substrates for $24 \mathrm{~h}$ showing an unhealthy round morphology and no spindle like form as on the bioactive glass as reference material. These observations were made in our experiments as well. We detected an increased $\mathrm{pH}$ level for AZ91D samples, up to 8.1 in osteogenic differentiation condition.

In biological studies, we verified after $24 \mathrm{~h}$ on $\mathrm{n}-\mathrm{HA}$ coated AZ91D a dense cell layer, comparable to cells on TCPS, whereas on non-modified samples no cells were detectable. After 14 days DNA was measurable in minor extend on n-HA coated AZ91D substrates. Fluorescence analysis however, to survey cell morphology, was not achievable in a satisfying extend possibly due to corrosion products that affect cell attachment. Nevertheless, we verified still a positive effect of the n-HA coating on the biological outcome even after 14 days of direct cell culture. Accelerated DNA and ALP amount was detected in comparison to the non-coated samples. This positive effect may be due to the higher protein absorption rate of HA according to Kilbadi et al. [42]. In their studies they examined the binding efficacy of different adhesion proteins to HA, titanium and stainless steel and revealed a better binding of fibronectin, vitronectin, $a_{5} \beta_{1}, a_{v} \beta_{3}$, and osteoblast precursor cells to HA than to the surveyed metals. An aspect leading to the decreased cell availability after 14 days may be the local $\mathrm{pH}$ change within the culture medium that has affected cell adhesion and viability. It has been shown previously that $\mathrm{pH}$ has an influence on cellular interactions [32]. Mg ions are released into the surrounding solution, prevalently within the first exposition days [35]. As $\mathrm{Mg}$ reacts with water $\mathrm{OH}^{-}$is produced that consequently leads to an increased $\mathrm{pH}$. Most likely, the high degradation products, gas production and a shift of the $\mathrm{pH}$ in the medium lead to cell detachment in our in vitro examinations that could not be prevented by the n-HA coating.

So far, to best of our knowledge, no direct cell culture studies were performed analyzing cell behavior after 14 days on Mg alloys. Our set up is suitable and reliable to test non-degradable materials, as shown by the Titaniumreference. After 14 days dense cell layers were verified on the material and the ALP expression was significant higher in osteogenic differentiated cells. Our results for AZ91D samples, however, must be critical considered as morphological analysis could hardly be realized. Even if DNA and ALP was detected after 14 days, we propose to modify the n-HA coating to further detain the degradation. Either a thicker $\mathrm{n}$-HA coating or a coating with a higher degree of crystallinity may result in superior and prolonged cell attachment and must be analyzed in future studies. For the purpose of enhancement of thin RF magnetron sputter deposited films crystallinity, post deposition annealing is necessary (no annealing was done in this study). Crystallinity is known to be an important factor in the biological properties of HA coatings [43]. In addition, according to the study [44], more cells are adsorbed and proliferate on a well-crystallised HA coating than on an amorphous HA coating with comparable particle size. The reason for improved cellular activity might because post-heattreated HA coatings exhibit higher crystallinity, a rougher surface, and more nanoparticles than as-deposited coatings [45-47].

Additionally, the impact of the thickness of n-HA coatings on coating integrity and degradation velocity must be examined in in vitro and preferable in in vivo experiments. As complex physiological conditions prevail in the in vivo situation, the outcome of in vitro test must be carefully estimated. For example a micro-arc-oxidized magnesium implant revealed a slower degradation rate in the first week in vivo, accelerated corrosion was not observed until the third week [48]. A review about the comparability of in vitro and in vivo tests concerning corrosion of $\mathrm{Mg}$ and $\mathrm{Mg}$ alloys addressed the challenge of in vitro predictions [49]. They concluded that generally a slower degradation rate takes 
place in vivo. A better simulation of the in vivo situation would be beneficial for in vitro testing to predict the performance of degradable implant materials in vivo. Prolonged culture times, more controllable culture parameter such as a constant $\mathrm{pH}$ level must be implemented into an in vitro model. It would be interesting to consider a 3D test model to overcome the limitation of a 2D monolayer culture direct on the substrate that also may allow a prolonged cell culture.

\section{Materials and methods}

\section{Coatings fabrication and characterization}

AZ91D magnesium alloy and titanium (Grade 4) were used as substrate. AZ91D alloy was purchased from DSM (Israel Chemicals Ltd), titanium from Goodfellow (purity 99.6+ \%). All the chemicals which were used to prepare hydroxyapatite powder for target are of p.a. qualities and have been purchased from Sigma-Aldrich (Germany). The titanium samples were chemically acid-etched for $5-10 \mathrm{~s}$ in a mixture of hydrofluoric acid (HF) and $\mathrm{HNO}_{3}$ acids. The acid mixture ratio of $\mathrm{HF}$ ( $48 \%$ concentration): $\mathrm{HNO}_{3}\left(65 \%\right.$ concentration): $\mathrm{H}_{2} \mathrm{O}$ was set to 1:4:5 in volume. The substrates were then cleaned ultrasonically in a diluted acetone bath for $30 \mathrm{~min}$ at $100^{\circ} \mathrm{C}$. The substrates were ultrasonically cleaned a second time in ethanol followed by rinsing in distilled water. Pure HA target was prepared according to the procedures described before [50]. A commercially available apparatus with an $\mathrm{RF}$ (13.56 MHz, COMDEL) magnetron source was used to deposit the HA coatings. The coating was fabricated at an RF-power level of $500 \mathrm{~W}$ in argon atmosphere (0.1 Pa) for $8 \mathrm{~h}$ onto a substrate mounted in a grounded substrate holder, which resulted in the coating thickness of $650 \pm 50 \mathrm{~nm}$ thick.

The surface morphology and surface composition of the deposited coatings were investigated using a field emission scanning electron microscope (FE-SEM, LEO $1530 \mathrm{VP}$ ) equipped with energy dispersive X-ray spectroscopy (EDAX, Phoenix).

The phase composition and the structure of the CaP coatings were identified by X-ray diffraction (XRD-7000, Shimadzu, Japan) with $\mathrm{CuK} \alpha$ radiation $(\lambda=0.154 \mathrm{~nm})$ in Bragg-Brentano mode and $2 \Theta$ range from $10^{\circ}$ to $60^{\circ}$ with a scan speed of $2.0^{\circ} / \mathrm{min}$, sampling pitch of $0.02^{\circ}$, preset time of $1.0 \mathrm{~s}$ at $30 \mathrm{kV}$ and $30 \mathrm{~mA}$. As reference for the pattern of HA we used the ICDD database: \#9-0432.

Optical ellipsometry (Ellipse 1891-S AG, Institute of Semiconductor Physics, RAS, Siberian Branch) was used to determine the thickness of the deposited coatings. Ellipsometric measurements were performed at an incidence angle of $70^{\circ}$ and over the wavelength region of $250-1000 \mathrm{~nm}$ with a spectral resolution of $2 \mathrm{~nm}$. The coating thickness was derived from the changes in ellipsometric parameters between the bare and coated substrates with a three-phase model (substrate-layer-air) [51]. Single-crystal (100) silicon wafers were used as substrates for the thickness measurements.

\section{Sterilization and pre-incubation}

For biological analysis, samples were placed in 6-well tissue culture plates for gamma sterilization ( $25 \mathrm{kGy}$ ). The sterilization was performed by BBF Bestrahlungsservice $\mathrm{GmbH}$ (Rommelshausen, Germany). A pre-incubation was performed in DMEM (Biochrom AG, Berlin, Germany) with 10\% fetal calf serum (Lonza, Verviers, Belgium) for $72 \mathrm{~h}$. Before cell seeding, the medium was aspirated.

\section{Isolation, culture and characterization of hMSCs}

Bone marrow aspirate - from two male 24 and 25 years old, and one female 45 years old healthy donors - was purchased from Lonza (Walkersville, USA) and human mesenchymal stem cells (hMSCs) were isolated by density centrifugation and plastic adherence according to (19). Cell culture was conducted in mesenchymal stem cell medium (MSCGM ${ }^{\mathrm{TM}}$ Bullet Kit ${ }^{\mathrm{TM}}$, Lonza, Verviers, Belgium), supplemented with 2\% (v/v) FCS, 50 units/mL penicillin, and $50 \mu \mathrm{g} / \mathrm{mL}$ streptomycin from Life Technologies (Darmstadt, Germany).

Cells were tested for purity by flow cytometry and for their ability to differentiate into osteogenic, chondrogenic, and adipogenic lineages. Fluorescence-activated cell sorting (FACS) was performed using antibodies against CD73 (BD, Heidelberg, Germany), CD90, CD105 CD14, CD19, CD34 and CD45 (all from Beckman Coulter, Krefeld, Germany). $2 \times 10^{5}$ cells were stained with $1 \mu \mathrm{g}$ of antibody by incubation for $20 \mathrm{~min}$ at room temperature, diluted in stain buffer (FBS, BD Pharmingen, Heidelberg, Germany). An isotype control against IgG1 as well as cells without any antibody were used as negative control. Cells were positive for CD73, CD90 and CD105 and negative for CD14, CD19, CD34, and CD45.

\section{Seeding of the material}

A total of $80 \mu \mathrm{L}$ hMSCs $\left(5 \times 10^{5}\right.$ cells $\left./ \mathrm{mL}\right)$ in human stem cell medium was pipetted onto the defined growth area of $1 \mathrm{~cm}^{2}$ of each sample TCPS dishes served as a control. The cells were allowed to attach for $3 \mathrm{~h}$ in humidified atmosphere $\left(37^{\circ} \mathrm{C}, 5 \% \mathrm{CO}_{2}\right)$. Thereafter, each sample was immersed in $4 \mathrm{~mL}$ human stem cell medium and cultured for $24 \mathrm{~h}$ or 14 days.

\section{Osteogenic differentiation and culture}

To induce osteogenic differentiation the medium was replaced after $24 \mathrm{~h}$ with hMSCs osteogenic differentiation medium (hMSC Osteogenic BulletKit, Lonza, Verviers, Belgium). As negative control, samples were cultured in proliferation medium consisting of DMEM supplemented with $10 \%$ FCS, 50 units/mL penicillin, and $50 \mu \mathrm{g} / \mathrm{mL}$ streptomycin (Life Technologies, Darmstadt, Germany). Medium was changed twice a week.

\section{Quantification of ALP}

The osteogenic differentiation capacity of hMSCs was determined at day 1 and 14 by analyzing ALP activity. ALP is a generally used marker for early osteogenic differentiation. The quantitative ALP analysis was performed using the SensoLyte ${ }^{\circledast}$ pNPP Alkaline Phosphatase 
Assay Kit (Mobitec, Göttingen, Germany). For cell lysis, seeded materials were washed once with DPBS and transferred in fresh 12 well tissue culture plates filled with $150 \mu \mathrm{L}$ collagenase NB4 $(500 \mathrm{U} / \mathrm{mL})$ (Serva, Heidelberg, Germany) and incubated for $90 \mathrm{~min}$ in an incubator $\left(37^{\circ} \mathrm{C}, 5 \% \mathrm{CO}_{2}\right)$, following an addition of $350 \mu \mathrm{L}$ lysis buffer (assay buffer of the kit, supplemented with 1\% NP-40 (Calbiochem, MerckMillipore, Darmstadt, Germany)) and incubation at $4^{\circ} \mathrm{C}$ for $1 \mathrm{~h}$. Lysed samples were collected, centrifuged for $5 \mathrm{~min}$ at $16,000 \times \mathrm{g}$ at $4^{\circ} \mathrm{C}$ and supernatant was transferred in new reaction tubes and used for quantitative ALP analysis and the analysis of DNA content. Performance of the ALP measurement was carried out according to the kit instructions. The results were measured at $405 \mathrm{~nm}$ in a Tecan Infinite 200 pro microplate reader (Tecan Deutschland GmbH, Crailsheim, Germany). ALP content was indicated as ng ALP/ $\mu$ g DNA.

\section{Quantification of DNA}

ALP content of the samples was normalized to the quantified DNA using the Quant-iT ${ }^{\mathrm{TM}}$ PicoGreen ${ }^{\circledR}$ dsDNA Assay Kit (Life Technologies, Darmstadt, Germany). DNA measurement was done according to the supplier's manual. The measurement was carried out at $480 \mathrm{~nm}$ excitation and $520 \mathrm{~nm}$ emission in a Tecan Infinite 200 pro microplate reader (Tecan Deutschland GmbH, Crailsheim, Germany).

\section{Actin-Vinculin-Staining}

To evaluate cell material interaction, cell adhesion was examined $24 \mathrm{~h}$ after seeding and after 14 days of cell culture in proliferation medium and osteogenic differentiation medium. Cells were washed once with Dulbecco's PBS (DPBS) (Biochrom GmbH, Berlin, Germany) and fixed with Histofix ${ }^{\circledast}$ (Roth, Karlsruhe, Germany) for 10 min. Fixed samples were washed twice and permeabilized for $10 \mathrm{~min}$ in Triton X100 solution (0.5\% in DPBS). After two washing steps, samples were incubated with 1:50 diluted phalloidin Alexa Fluor ${ }^{\circledR} 546$ (LifeTechnologies, Darmstadt, Germany) in antibody diluent (Dako, Hamburg, Germany) for $1 \mathrm{~h}$ at room temperature.

Samples were rinsed three times with DPBS, followed by an incubation step with 1:50 diluted Vinculin-FITC conjugated antibody (Sigma-Aldrich, Munich, Germany) in antibody diluent for $1 \mathrm{~h}$. After three washing steps with DPBS, staining of nuclei with DAPI (SigmaAldrich, München, Germany) at a concentration of $1 \mu \mathrm{g} / \mathrm{mL}$ in DPBS for $15 \mathrm{~min}$ was carried out. The samples were rinsed two times with DPBS and analyzed by using a Zeiss LSM 700 confocal microscope. For LSM microscopy we used an argon laser taking the same adjustments for all samples. Filter sets of 429-492 nm (DAPI), 495-553 nm (FITC) and 566-680 nm (AlexaF) were used. A wavelength of $561 \mathrm{~nm}$ was applied for actin detections whereas a wavelength of $488 \mathrm{~nm}$ was taken to excite the fluorophore coupled to vinculin.

\section{pH assessment}

During the experiment period of 14 days, the $\mathrm{pH}$ of each medium (osteogenic and control medium) was measured twice a week before medium exchange by a pH meter (Greisinger GMH 550, Regenstrauf, Germany). Pure medium was measured simultaneously.

\section{Statistics}

The biological experiments were repeated three times using three different donors whereas for each donor three replicates were analyzed. Statistical significant differences were assessed by the software OriginPro 8G using the one factor analysis of variance (ANOVA) applying post hoc Fishers LSD test. The data were expressed as mean values \pm SD. $p$-Values $<0.05$ were defined as statistically significant. A significant difference between two experiment groups is denoted with ${ }^{\star} \mathrm{p}<0.05 ;{ }^{\star \star} \mathrm{p}<0.01$.

Acknowledgments: The authors kindly thank S. Layland for proof reading the manuscript and V.P. Ignatov, Dr. M. Müller, V. Schönhaar, and A.A. Sharonova for the help with the substrates preparation for RF-magnetron sputtering. This work was supported by the Fraunhofer Internal Programs (Grant No. MAVO DegraLast 824682) and State Order NAUKA (\#11.1359.2014/K) and the Russian President's Stipend SP-6664.2013.4 and MK-485.2014 for the assistance with the fabrication of CaP-based coatings.

\section{References}

1. Kraus T, Fischerauer SF, Hanzi AC, Uggowitzer PJ, Loffler JF, Weinberg AM. Magnesium alloys for temporary implants in osteosynthesis: in vivo studies of their degradation and interaction with bone. Acta Biomater 2012;8:1230-8.

2. Hou L, Li Z, Pan Y, Du L, Li X, Zheng Y. et al. In vitro and in vivo studies on biodegradable magnesium alloy. Prog Nat Sci Mater Int 2014;24:466-71.

3. Windhagen H, Radtke K, Weizbauer A, Diekmann J, Noll Y, Kreimeyer $\mathrm{U}$, et al. Biodegradable magnesium-based screw clinically equivalent to titanium screw in hallux valgus surgery: short term results of the first prospective, randomized, controlled clinical pilot study. Biomed Eng Online 2013;12:62.

4. Waizy H, Diekmann J, Weizbauer A, Reifenrath J, Bartsch I, Neubert $\mathrm{V}$, e al. In vivo study of a biodegradable orthopedic screw (MgYREZr-alloy) in a rabbit model for up to 12 months. J Biomater Appl 2014;28:667-75.

5. Fischer J, Prosenc MH, Wolff M, Hort N, Willumeit R, Feyerabend F. Interference of magnesium corrosion with tetrazolium-based cytotoxicity assays. Acta Biomater 2010;6:1813-23.

6. Richard H, Diana M, Simon L, Yufeng Z, Yang L. Corrosion of magnesium and magnesium-calcium alloy in biologicallysimulated environment. Prog Nat Sci Mater Int 2014;24:539-46.

7. Wang B, Huang P, Ou C, Li K, Yan B, Lu W. In vitro corrosion and cytocompatibility of ZK60 magnesium alloy coated with hydroxyapatite by a simple chemical conversion process for orthopedic applications. Int J Mol Sci 2013;14:23614-28.

8. Pichler K, Kraus T, Martinelli E, Sadoghi P, Musumeci G, Uggowitzer PJ, et al. Cellular reactions to biodegradable magnesium alloys on human growth plate chondrocytes and osteoblasts. Int Orthop 2014;38:881-9.

9. Li RW, Kirkland NT, Truong J, Wang J, Smith PN, Birbilis N, et al. The influence of biodegradable magnesium alloys on the 
osteogenic differentiation of human mesenchymal stem cells. J Biomed Mater Res A 2014;102:4346-57.

10. Tie D, Feyerabend F, Hort N, Hoeche D, Kainer KU, Willumeit R, et al In vitro mechanical and corrosion properties of biodegradable Mg-Ag alloys. Mater Corr 2014;65:569-76.

11. Campo RD, Savoini B, Munoz A, Monge MA, Garces G. Mechanical properties and corrosion behavior of Mg-HAP composites. J Mech Behav Biomed Mater 2014;39:238-46.

12. Liu G-Y, Tang S-W, Wang C, Hu J, Li D-C. Formation characteristic of Ca-P coatings on magnesium alloy surface. T Nonferr Metal Soc 2013;23:2294-9.

13. Liu X, Yue Z, Romeo T, Weber J, Scheuermann T, Moulton S, et al. Biofunctionalized anti-corrosive silane coatings for magnesium alloys. Acta Biomater 2013;9:8671-7.

14. Ostrowski NJ, Lee B, Roy A, Ramanathan M, Kumta PN. Biodegradable poly(lactide-co-glycolide) coatings on magnesium alloys for orthopedic applications. J Mater Sci Mater Med 2013;24:85-96.

15. Dorozhkin SV. Calcium orthophosphate coatings on magnesium and its biodegradable alloys. Acta Biomater 2014;10:2919-34.

16. Wang PY, Li WT, Yu J, Tsai WB. Modulation of osteogenic, adipogenic and myogenic differentiation of mesenchymal stem cells by submicron grooved topography. J Mater Sci Mater Med 2012;23:3015-28.

17. de Peppo GM, Agheli H, Karlsson C, Ekstrom K, Brisby H, Lenneras $M$, et al. Osteogenic response of human mesenchymal stem cells to well-defined nanoscale topography in vitro. Int J Nanomedicine 2014;9:2499-515.

18. Faghihi F, Baghaban Eslaminejad M. The effect of nano-scale topography on osteogenic differentiation of mesenchymal stem cells. Biomed Pap Med Fac Univ Palacky Olomouc Czech Repub 2014;158:5-16.

19. Kleinhans C, Barz J, Wurster S, Willig M, Oehr C, Muller M, et al. Ammonia plasma treatment of polystyrene surfaces enhances proliferation of primary human mesenchymal stem cells and human endothelial cells. Biotechnol J 2013;8:327-37.

20. Steinmuller-Nethl D, Kloss FR, Najam-Ul-Haq M, Rainer M, Larsson K, Linsmeier C, et al. Strong binding of bioactive BMP-2 to nanocrystalline diamond by physisorption. Biomaterials 2006;27:4547-56.

21. Zamani Y, Rabiee M, Shokrgozar MA, Bonakdar S, Tahriri M. Response of human mesenchymal stem cells to patterned and randomly oriented poly(vinyl alcohol) nano-fibrous scaffolds surface-modified with Arg-Gly-Asp (RGD) ligand. Appl Biochem Biotechnol 2013;171:1513-24.

22. Kannan MB, Orr L. In vitro mechanical integrity of hydroxyapatite coated magnesium alloy. Biomed Mater 2011;6:045003.

23. Salman SA, Kuroda K, Okido M. Preparation and characterization of hydroxyapatite coating on AZ31 Mg alloy for implant applications. Bioinorg Chem Appl 2013;2013:175756.

24. Surmenev RA. A review of plasma-assisted methods for calcium phosphate-based coatings fabrication. Surf Coat Tech 2012;206:2035-56.

25. Surmeneva MA, Chaikina MV, Zaikovskiy VI, Pichugin VF, Prymak O, Epple M, et al. The structure of an RF-magnetron sputter-deposited silicate-containing hydroxyapatite-based coating investigated by high-resolution techniques. Surf Coat Tech 2013;218:39-46.

26. Long JD, Xu S, Cai JW, Jiang N, Lu JH, Ostrikov KN, et al. Structure, bonding state and in-vitro study of Ca-P-Ti film deposited on Ti6Al4V by RF magnetron sputtering. Mater Sci Eng C 2002;20:175-80.

27. Coelho PG, Suzuki M. Evaluation of an IBAD thin-film process as an alternative method for surface incorporation of bioceramics on dental implants. A study in dogs. J Appl Oral Science 2005;13:87-92.

28. Coelho PG, Cardaropoli G, Suzuki M, Lemons JE. Early healing of nanothickness bioceramic coatings on dental implants. An experimental study in dogs. J Biomed Mater Res Part B Appl Biomater 2009;88B:387-93.

29. Surmeneva MA, Surmenev RA, Tyurin Al, Mukhametkaliyev TM, Teresov AD, Koval NN, et al. Comparative study of the radiofrequency magnetron sputter deposited CaP films fabricated onto acid-etched or pulsed electron beam-treated titanium. Thin Solid Films. 2014;571:218-24.

30. Surmeneva MA, Surmenev RA, Nikonova YA, Selezneva II, Ivanovaa AA, Putlyaev VI, et al. Fabrication, ultra-structure characterization and in vitro studies of RFmagnetron sputter deposited nano-hydroxyapatite thin films forbiomedical applications. Appl Surf Sci 2014;317:172-80.

31. Li L, Gao J, Wang Y. Evaluation of cyto-toxicity and corrosion behavior of alkali-heat-treated magnesium in simulated body fluid. Surf Coat Tech 2004;185:92-8.

32. Johnson I, Perchy D, Liu H. In vitro evaluation of the surface effects on magnesium-yttrium alloy degradation and mesenchymal stem cell adhesion. J Biomed Mater Res A 2012;100:477-85.

33. Cipriano AF, Zhao T, Johnson I, Guan RG, Garcia S, Liu H. In vitro degradation of four magnesium-zinc-strontium alloys and their cytocompatibility with human embryonic stem cells. J Mater Sci Mater Med 2013;24:989-1003.

34. Cipriano AF, Sallee A, Guan RG, Zhao ZY, Tayoba M, Sanchez J, et al. Investigation of magnesium-zinc-calcium alloys and bone marrow derived mesenchymal stem cell response in direct culture. Acta Biomater 2015;12:298-321.

35. Xin Y, Liu C, Zhang X, Tang G, Tian X, Chu PK. Corrosion behavior of biomedical AZ91 magnesium alloy in simulated body fluids. J Mater Res 2011;22:2004-11.

36. Surmenev RA, Ryabtseva MA, Shesterikov EV, Pichugin VF, Peitsch T, Epple M. The release of nickel from nickel-titanium (NiTi) is strongly reduced by a sub-micrometer thin layer of calcium phosphate deposited by rf-magnetron sputtering. J Mater Sci Mater Med 2010;21:1233-9.

37. Johnson I, Akari K, Liu H. Nanostructured hydroxyapatite/ poly(lactic-co-glycolic acid) composite coating for controlling magnesium degradation in simulated body fluid. Nanotechnology 2013;24:375103.

38. Rojaee R, Fathi M, Raeissi K. Electrophoretic deposition of nanostructured hydroxyapatite coating on AZ91 magnesium alloy implants with different surface treatments. Appl Surf Sci 2013;285:664-73.

39. Rojaee R,. Fathi M, Raeissi K. Comparing nanostructured hydroxyapatite coating on AZ91 alloy samples via Sol-gel and electrophoretic deposition for biomedical applications. IEEE Trans Nanobioscience 2014;13:409-14.

40. Gopi D, Murugan N, Ramya S, Kavitha L. Electrodeposition of a porous strontium-substituted hydroxyapatite/zinc oxide duplex layer on AZ91 magnesium alloy for orthopedic applications. J Mater Chem B 2014;2:5531.

41. Iskandar ME, Aslani A, Liu H. The effects of nanostructured hydroxyapatite coating on the biodegradation and cyto- 
compatibility of magnesium implants. J Biomed Mater Res A 2013;101:2340-54.

42. Kilpadi KL, Chang PL, Bellis SL. Hydroxylapatite binds more serum proteins, purified integrins, and osteoblast precursor cells than titanium or steel. J Biomed Mater Res 2001;57:258-67.

43. Xue W, Liu X, Zheng X, Ding C. Effect of hydroxyapatite coating crystallinity on dissolution and osseointegration in vivo. J Biomed Mater Res A 2005;54:553-61.

44. Hu Q, Tan Z, Liu Y, Tao J, Cai Y, Zhang M, et al. Effect of crystallinity of calcium phosphate nanoparticles on adhesion, proliferation, and differentiation of bone marrow mesenchymal stem cells. J Mater Chem 2007;17:4690-8.

45. Lo WJ, Grant DM, Ball MD, Welsh BS, Howdle SM, Antonov EN, et al. Physical, chemical, and biological characterization of pulsed laser deposited and plasma sputtered hydroxyapatite thin films on titanium alloy. J Biomed Mat Res 2000;50:536-45.

46. Yan Y, Wolke JGC, De Ruijter A, Yubao L, Jansen JA. Growth behavior of rat bone marrow cells on RF magnetron sputtered hydroxyapatite and dicalcium pyrophosphate coatings.

J Biomed Mat Res Part A 2006;78A:42-9.

47. Lu YP, Chen YM, Li ST, Wang JH. Surface nanocrystallization of hydroxyapatite coating. Acta Biomaterialia 2008;4:1865-72.

48. Fischerauer SF, Kraus T, Wu X, Tangl S, Sorantin E, Hanzi AC, et al. In vivo degradation performance of micro-arc-oxidized magnesium implants: a micro-CT study in rats. Acta Biomater 2013;9:5411-20.

49. Sanchez AH, Luthringer BJ, Feyerabend F, Willumeit R. Mg and $M g$ alloys: How comparable are in vitro and in vivo corrosion rates? A review. Acta Biomater. 2015;13:16-31.

50. Surmenev RA, Surmeneva MA, Evdokimov KE, Pichugin VF, Peitsch T, Epple M. The influence of the deposition parameters on the properties of an rf-magnetron-deposited nanostructured calcium phosphate coating and a possible growth mechanism. Surf Coat Tech 2011;205:3600-6.

51. Bu-Abbud GH, Bashara NM, Woollam JA. Variable wavelength, variable angle ellipsometry including a sensitivities correlation test. Thin Solid Films 1986;138:27-41. 